\title{
Equity of access to primary healthcare for vulnerable populations: the IMPACT international online survey of innovations
}

\author{
Lauralie Richard $^{1 *}$, John Furler ${ }^{1}$, Konstancja Densley ${ }^{1}$, Jeannie Haggerty², Grant Russell ${ }^{3}$, \\ Jean-Frederic Levesque ${ }^{4,5}$ and Jane Gunn ${ }^{1}$
}

\begin{abstract}
Background: Improving access to primary healthcare (PHC) for vulnerable populations is important for achieving health equity, yet this remains challenging. Evidence of effective interventions is rather limited and fragmented. We need to identify innovative ways to improve access to PHC for vulnerable populations, and to clarify which elements of health systems, organisations or services (supply-side dimensions of access) and abilities of patients or populations (demand-side dimensions of access) need to be strengthened to achieve transformative change. The work reported here was conducted as part of IMPACT (Innovative Models Promoting Access-to-Care Transformation), a 5-year Canadian-Australian research program aiming to identify, implement and trial best practice interventions to improve access to PHC for vulnerable populations. We undertook an environmental scan as a broad screening approach to identify the breadth of current innovations from the field.
\end{abstract}

Methods: We distributed a brief online survey to an international audience of PHC researchers, practitioners, policy makers and stakeholders using a combined email and social media approach. Respondents were invited to describe a program, service, approach or model of care that they considered innovative in helping vulnerable populations to get access to PHC. We used descriptive statistics to characterise the innovations and conducted a qualitative framework analysis to further examine the text describing each innovation.

Results: Seven hundred forty-four responses were recorded over a 6-week period. 240 unique examples of innovations originating from 14 countries were described, the majority from Canada and Australia. Most interventions targeted a diversity of population groups, were government funded and delivered in a community health, General Practice or outreach clinic setting. Interventions were mainly focused on the health sector and directed at organisational and/or system level determinants of access (supply-side). Few innovations were developed to enhance patients' or populations' abilities to access services (demand-side), and rarely did initiatives target both supply- and demand-side determinants of access.

Conclusions: A wide range of innovations improving access to PHC were identified. The access framework was useful in uncovering the disparity between supply- and demand-side dimensions and pinpointing areas which could benefit from further attention to close the equity gap for vulnerable populations in accessing PHC services that correspond to their needs.

Keywords: Access, Primary healthcare, Vulnerable populations, Innovations, Environmental scan, Online survey

\footnotetext{
* Correspondence: lauralierichard@gmail.com

'Primary Care Research Unit, Department of General Practice, Faculty of

Medicine, Dentistry and Health Sciences, University of Melbourne, 200,

Berkeley street, Melbourne, VIC 3004, Australia

Full list of author information is available at the end of the article
} 


\section{Background}

A strong primary healthcare (PHC) system is paramount to optimising population health, yet $\mathrm{PHC}$ services are not always readily accessible $[1,2]$. Striking differences in health still exist within and between populations, and inequities in access to PHC persist and tend to affect the most vulnerable ${ }^{1 \mathrm{a}}$ people in our communities, those with the most complex healthcare needs [3-5]. This was famously captured in the Inverse Care Law [6] which suggests that those with the greatest need often have, paradoxically, the poorest utilisation of healthcare services. From a human rights perspective, access to healthcare should be within reach of all, regardless of race, gender, culture, religion, political belief or socioeconomic condition [7]. Inextricably linked with access to healthcare is the notion of equity, which gives emphasis to its underpinning values of fairness and social justice [8-10].

Improving access to $\mathrm{PHC}$ has been on the global agenda for decades. It has been integrated as a central component to many contemporary health agreements (e.g. [11, 12]) and translated into substantial health service reforms internationally. Notwithstanding these efforts, there remains little evidence of equity of access to $\mathrm{PHC}$ at a population level. Furthermore, interventions designed to improve access to $\mathrm{PHC}$ for vulnerable populations are often highly fragmented and under-resourced [13-19]. Inequitable access to healthcare translates into unmet healthcare needs, worse and inequitable health outcomes and increased healthcare costs [20-22].

Equity of access to PHC is a major social determinant of health and is considered as a strategy for addressing health inequity [23]. The PHC sector as a whole has a responsibility to promote health equity as part of its social mandate [1]. This means developing interventions which support access via fair arrangements based on equal access to healthcare for all in equal need. Determinants of access to healthcare are amenable to change, both at a system level (e.g. transforming the way that health systems and organisations function; supporting the development of new professional roles and expanded scope of practice) and at an individual or population level (e.g. empowering patients to participate in decisionmaking processes regarding their care; advocating for community-led services). However, we are still striving to find effective ways of reaching equity of access to $\mathrm{PHC}$ to support those most in need, and to identify which aspects of services and abilities of people to strengthen in order to achieve transformative change.

The literature on access to healthcare is abundant, diverse and complex, offering varying definitions and conceptualisations [24-30]. In general, access can be defined as the opportunity or ease with which consumers or communities are able to use appropriate services in proportion to their need. In the past, it has been characterised with an emphasis on either attributes of health systems, organisations, services and providers (supply-side determinants of access) or abilities of individuals and populations to access services (demand-side determinants of access). More recently, a framework has been proposed that integrates both supply- and demandside determinants in an attempt to capture the complexity of the phenomenon in the context of healthcare systems in perpetual transformation [24]. In line with an equity perspective [5, 31-34], conceptual frameworks of access should direct attention to demographic, social, economic, geographic and cultural factors which may structure the experience and opportunities of different social groups to reach and obtain appropriate healthcare [24, 31, 33, 34].

IMPACT (Innovative Models Promoting Access-toCare Transformation) is a 5-year research program which brings together researchers in PHC, health services research and implementation science together with communities of practice in six regions in Canada and Australia. The aims of the research are to identify, refine and then trial best practice innovations to assist access to $\mathrm{PHC}$, particularly for vulnerable populations. Here we report on the findings of an international online survey (referred to here as an environmental scan) of innovative interventions reported as enhancing access to $\mathrm{PHC}$ for vulnerable populations, undertaken as part of IMPACT Project 1 - Scoping the innovations. Our aim was to identify the breadth of innovations from the field. Environmental scanning is a research approach that uses wide-scope screening methods to identify the new, the unexpected and the emerging interventions, issues and challenges in health [35]. This study was developed as complementary to a scoping review of the published literature on access interventions, conducted independently of the environmental scan. Our rationale was that innovations may exist at the local, state and national levels while remaining undocumented in the literature.

\section{Methods \\ Survey design}

A brief 5-min online survey (see Additional file 1) was developed and hosted on Qualtrics, an online survey design software, which was selected for its ease of use and the quality of its user interface. A collaborative approach was chosen to design the survey. The IMPACT research team members were invited to participate in drafting the survey introduction and survey questions, as well as discussing the preferable structure of the survey (e.g. number of sections, item format). This led to the development of an initial version of the survey, which was piloted within the research team. Comments and suggestions provided by the team helped to improve the survey before it was piloted more broadly 
within the Department of General Practice at the University of Melbourne (Australia), in order to further address any usability and design issues before the official survey launch. The survey involved participants identifying and describing, from their own experience, an example of a program, service, approach or model of care that they considered innovative in helping vulnerable populations to access PHC services that meet their needs. Respondents were invited to identify the most striking components or aspects of the innovation. Information details gathered about innovations were as followed: name of innovation, geographic location, setting in which it was delivered, population group(s) targeted, core activities and processes, description of its innovative aspects, source(s) of funding. There was also a section of the survey enquiring about how we could learn more about the innovation, including options for the respondents to add a link to a website, a report or any other documentation that they would consider relevant. Different options were also offered to respondents in terms of language preference (the survey was available in English and French) and item format to complete the survey, the latter comprised of a mix of multiple choice options combined with description boxes, for those respondents who wanted to provide us with more detailed information. The survey, kept short and precise to optimise participation, also included a section about demographics of respondents.

\section{Planning survey dissemination}

An iterative process involving the research team members and their networks was used to assemble an extensive email database of key PHC contacts, which included informants from $\mathrm{PHC}$ organisations, associations and university departments from Australia, Canada, UK and USA. Email contacts were then transferred into Qualtrics and email templates and schedules were created to facilitate survey dissemination $\left(1^{\text {st }}\right.$ email to raise awareness; $2^{\text {nd }}$ email initial contact with survey link, $3^{\text {rd }}$ email 2 -week reminder, $4^{\text {th }}$ email final reminder). A comprehensive Google search was also undertaken to identify relevant online and social media channels to promote the survey. A Twitter account was created to build a list of followers and relevant Twitter accounts to follow as part of the social media campaign, in preparation for the survey launch. The social media campaign used Buffer, a social media management tool (www.buffer.com), which helped coordinate pre-programmed messages via Twitter and advertisements on other online platforms such as Linkedin and Facebook to build momentum around the study, ensure a high presence on social media and maximise response rate.

\section{Survey dissemination}

The survey was disseminated widely amongst an international audience of PHC leaders, researchers, practitioners, policy makers and stakeholders using this combined email and social media approach. We also used a snowballing approach where the survey link would be shared within PHC networks and survey tweets would be commented on, liked and retweeted by a handful of followers, and then further shared by other people in extended networks, therefore increasing reach and visibility. The survey remained open for a 6-week period, from July $10^{\text {th }}$ to August $21^{\text {st }} 2014$.

\section{Inclusion criteria}

We deliberately decided not to use a predetermined definition of "innovation" so that we could identify, from the respondents' perspectives, initiatives that they considered had made a difference in helping people to achieve improved access to services. Our focus was on trying to collect information from people who might have experienced a wide range of potentially innovative interventions, from a user, design, delivery or evaluation perspective. We included all innovations which were PHC focussed, primarily aimed at improving access and targeting vulnerable populations in our analysis.

\section{Conceptual framework}

The Levesque et al. [24] access framework was used as the conceptual foundation for the study. The framework builds on previous conceptualisations of access (e.g. [25, 27, 30, 36-38], and is in continuous development with proposals which take into account social and health dimensions of access within an equity perspective [32]. Building on a comprehensive view of access articulated around factors pertaining to the healthcare system, individuals and context, the authors integrate both supply- and demand-side dimensions into their access framework, allowing operationalisation of access along the pathway of utilisation of care from perception of need through to the outcomes of service use. The framework is comprised of five dimensions of accessibility of care (approachability, acceptability, availability and accommodation, affordability, appropriateness) and five corresponding abilities of patients and populations to access care (ability to perceive, ability to seek, ability to reach, ability to pay, ability to engage) (Fig. 1). These dimensions of access are considered as interdependent constructs. The framework is arranged in pairs: each supply-side dimension of accessibility of care is mirrored by a matching demand-side ability of patients or populations to access services. The combination of a corresponding supply- and demand-side dimension is referred to here as "paired dimensions". Operational 


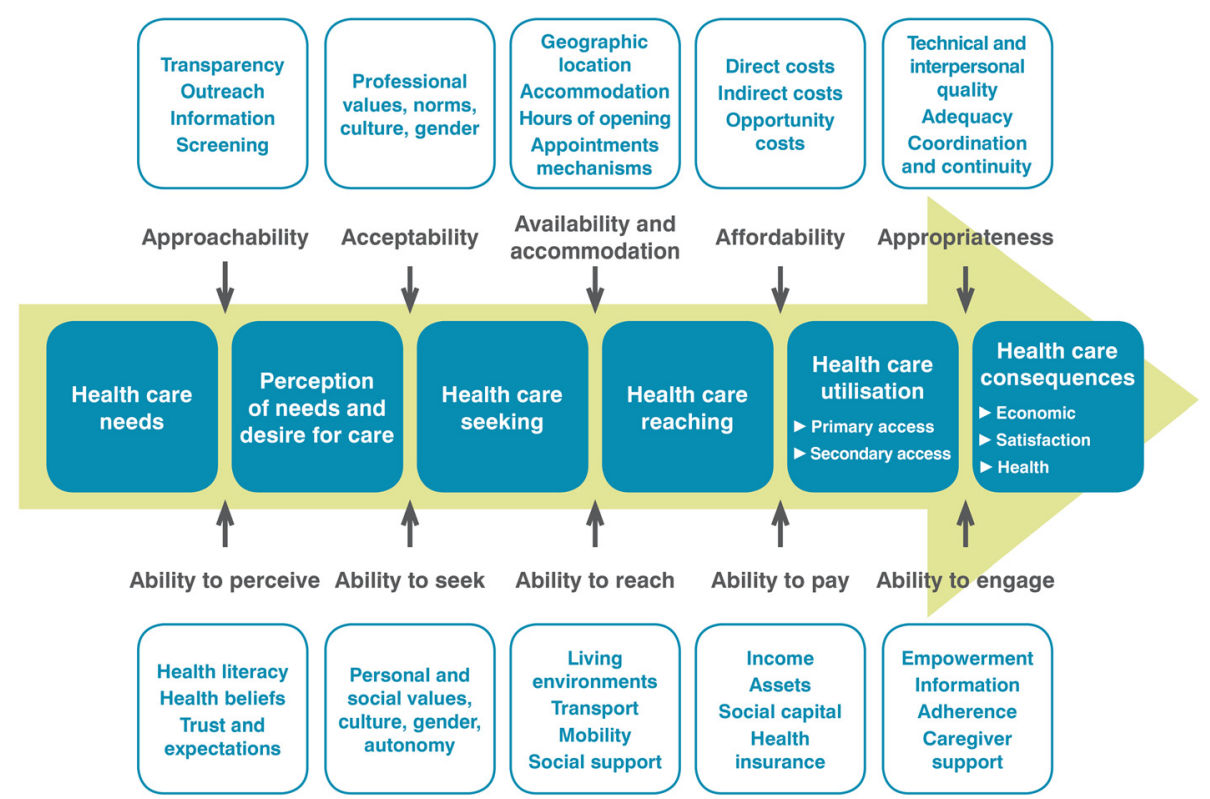

Fig. 1 Conceptualisation of access adapted from Levesque et al. [24]

definitions of each access dimension are described in Table 1.

\section{Analysis}

We conducted a framework analysis [39] based on the Levesque et al. [24] access framework to all included innovations. Written descriptions of innovations were mapped against the framework to identify which access dimensions were addressed. An innovation could address more than one dimension of the access framework. Each description of innovation was specifically examined to see if it addresses supply-side only, demand-side only, or paired dimensions of access. All data were double coded (LR and alternately JG, JF). Quotes from each description of innovation were used to support the coding process, and these were referred to when discrepancies arose between

Table 1 Definitions of access dimensions based on Levesque et a.l [24]

\begin{tabular}{|c|c|c|c|}
\hline $\begin{array}{l}\text { Supply-side dimensions } \\
\text { of accessibility of services }\end{array}$ & Definitions & $\begin{array}{l}\text { Demand-side abilities } \\
\text { of patients to access } \\
\text { services }\end{array}$ & Definitions \\
\hline Approachability & $\begin{array}{l}\text { Approachability of services relates to the fact } \\
\text { that people facing healthcare needs can } \\
\text { identify that some form of services exists, can } \\
\text { be reached, and have an impact on their health. }\end{array}$ & Ability to perceive & $\begin{array}{l}\text { Ability to perceive translates into the ability of } \\
\text { people to identify their needs for care. }\end{array}$ \\
\hline Acceptability & $\begin{array}{l}\text { Acceptability of services relates to social and } \\
\text { cultural factors determining the possibility for } \\
\text { people to accept the aspects of a service. }\end{array}$ & Ability to seek & $\begin{array}{l}\text { Ability to seek healthcare relates to factors that } \\
\text { would determine expressing the intention to } \\
\text { obtain healthcare. }\end{array}$ \\
\hline $\begin{array}{l}\text { Availability and } \\
\text { accommodation }\end{array}$ & $\begin{array}{l}\text { Availability and accommodation refers to the } \\
\text { fact that health services (either the physical } \\
\text { space or those working in healthcare roles) } \\
\text { can be reached both physically and in a } \\
\text { timely manner. }\end{array}$ & Ability to reach & $\begin{array}{l}\text { Ability to reach healthcare relates to factors that } \\
\text { would enable one person to physically reach } \\
\text { service providers. }\end{array}$ \\
\hline Affordability & $\begin{array}{l}\text { Affordability reflects the economic capacity } \\
\text { for people to spend resources and time to } \\
\text { use appropriate services. }\end{array}$ & Ability to pay & $\begin{array}{l}\text { Ability to pay for healthcare is described as the } \\
\text { capacity to generate economic resources to pay } \\
\text { for healthcare services without catastrophic } \\
\text { expenditure of resources required for basic } \\
\text { necessities. }\end{array}$ \\
\hline Appropriateness & $\begin{array}{l}\text { Appropriateness denotes the fit between } \\
\text { services and clients' needs, its timeliness, the } \\
\text { amount of care spent in assessing health } \\
\text { problems and determining the correct } \\
\text { treatment and the technical and interpersonal } \\
\text { quality of the services provided. }\end{array}$ & Ability to engage & $\begin{array}{l}\text { Ability to engage in healthcare relates to the } \\
\text { participation and involvement of the client in } \\
\text { decision-making and treatment decisions, which } \\
\text { is in turn strongly determined by capacity and } \\
\text { motivation to participate in care and commit to } \\
\text { its completion. }\end{array}$ \\
\hline
\end{tabular}


coders in order to reach agreement. The innovations were also assessed in terms of their implementation level - micro (local or practice level), meso (state or regional level), and macro (national level) - and in terms of whether they involved the participation of the health sector, the social sector or both sectors (i.e. multisectoral initiatives). Finally, components of interventions were identified inductively through the analysis process to further exemplify each dimension of access. Descriptive statistics were used to characterise the innovations according to: country of innovation, sectors involved, population group(s) targeted, setting(s) in which the innovation is delivered, implementation level, funding sources and access dimensions addressed. All statistical analyses were conducted using STATA version 12 [40].

This study received full ethics approval from the University of Melbourne Human Research Ethics Committee (1442125.1). Participation in the survey was voluntary and consent was obtained by respondents filling out and submitting their survey. Plain Language Statements (English and French) were linked to the first screen of the online survey and attached to the email invitations for easy access.

\section{Results}

Over 2000 emails were sent to key PHC informants and 248 tweets were posted on Twitter, creating a social media presence aimed at building interest in the survey topic. The social media campaign attracted 387 followers and the tweets were viewed 1189 times per week on average (Fig. 2). We recorded 744 survey responses over a 6-week period, describing 240 unique examples of innovations (Fig. 3).

The number of surveys completed correlated to the dates that email invitations and reminders were sent (Fig. 4). Following the lull between July $20^{\text {th }}$ and $26^{\text {th }}$, we modified our social media campaign strategy in varying the content of our tweets, sharing papers of interest and emerging findings to encourage completion of the survey.

The survey was mainly completed in English (89.2 \%). From the respondents who provided an example of innovation (name and description; $N=326), 233$ (71.5\%) completed the demographics section. Most respondents were from Canada (47.6 \%) and Australia (42.9\%). The majority of respondents were female (71.7 \%), aged between 35 and 54 years old (48.5\%), had completed a postgraduate degree $(72.1 \%)$, worked as a researcher (32.2\%), general practitioner (25.3\%), nurse (24.9\%), or as a manager of PHC services (18.5\%), and reported an initiative that they either designed, implemented or evaluated (47.3\%), delivered as part of a program or service (45.1\%), or used themselves (11.8\%). The demographics of the survey respondents are presented in Table 2.

\section{Characteristics of innovations}

The general characteristics of the innovations are shown in Table 3. As no major difference was found

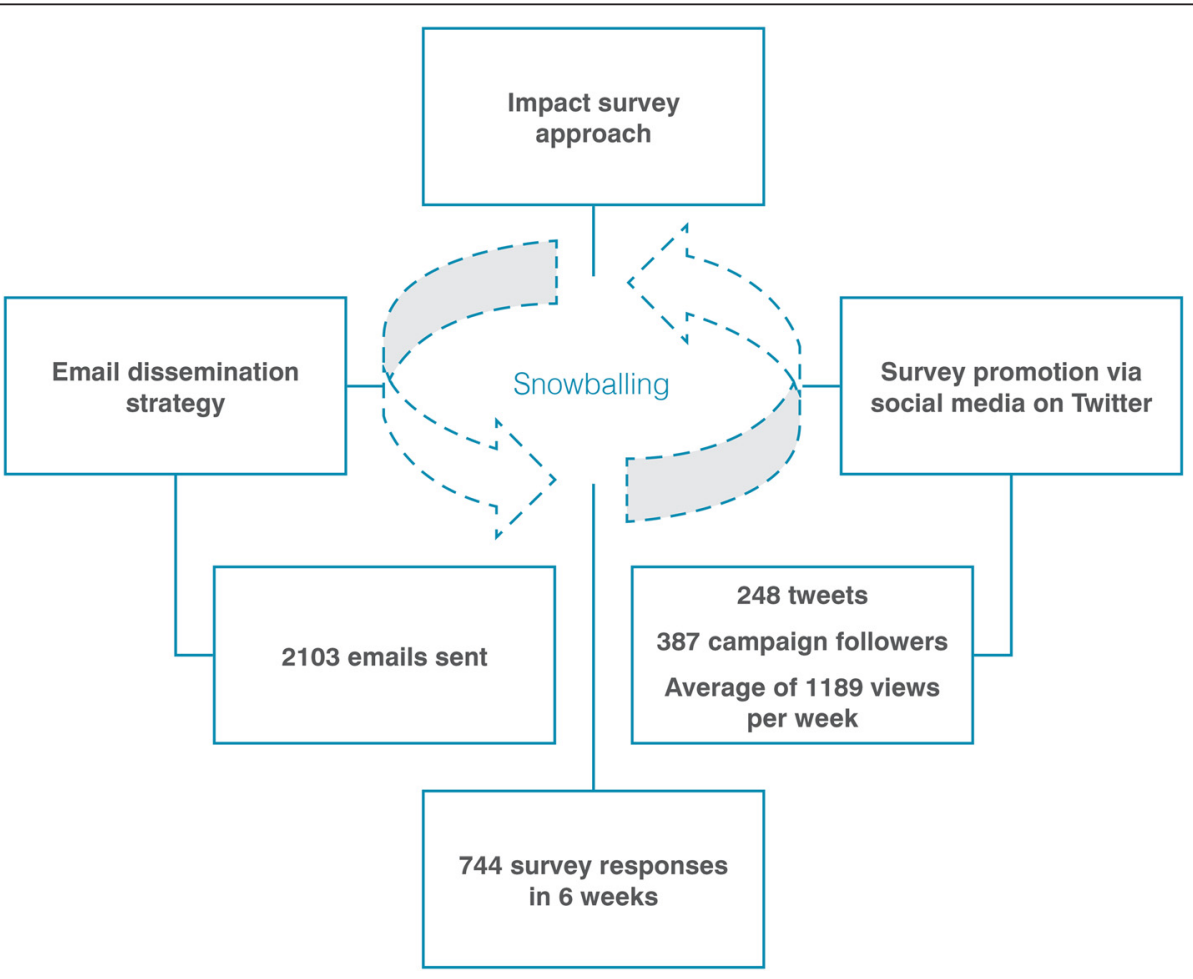

Fig. 2 Survey procedure 


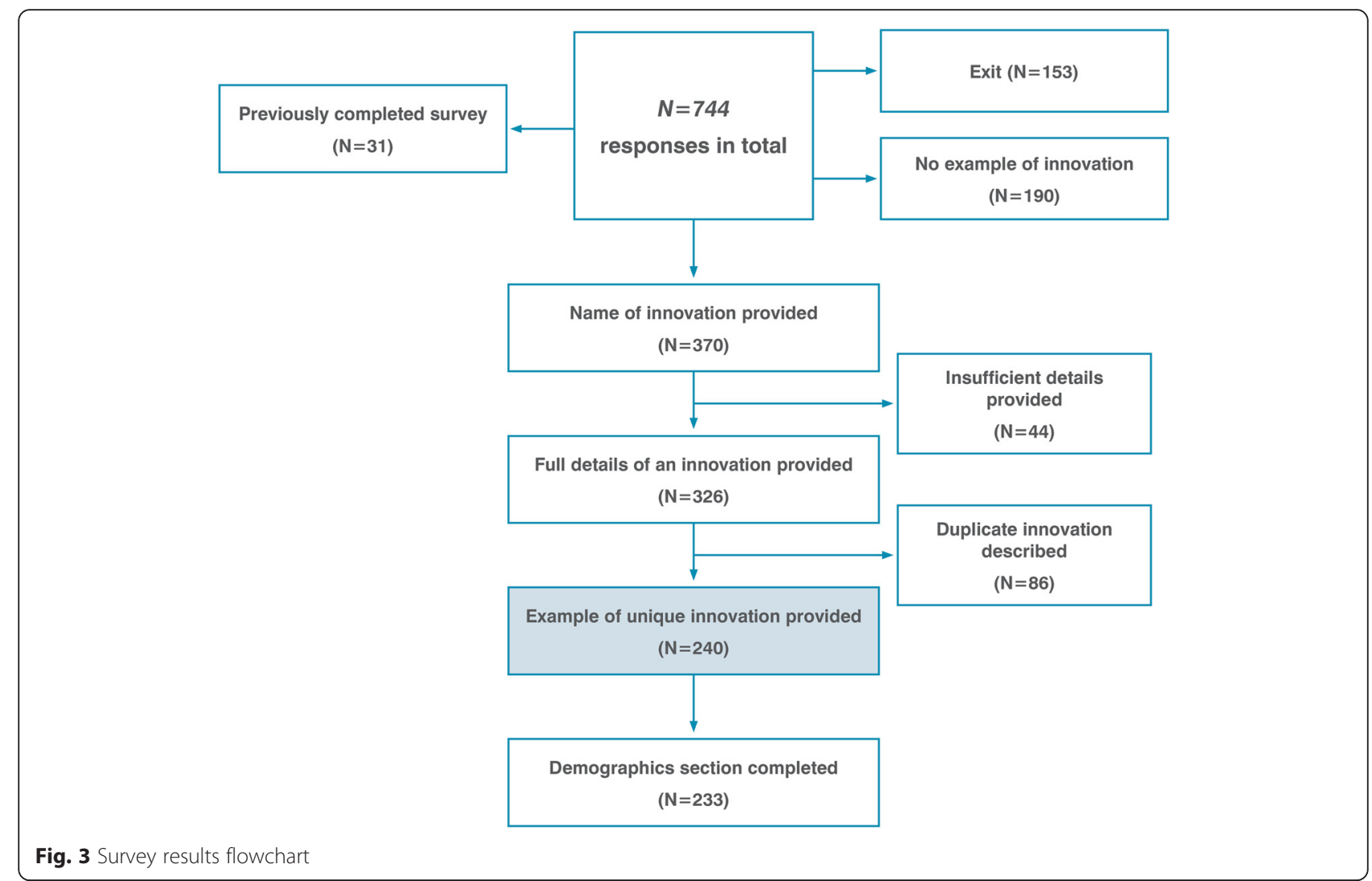

by country of origin, we have combined the findings from respondents from different countries.

\section{Country of innovations}

The innovations reported in the survey originated from 14 countries, with the majority coming from Canada (45.0 \%) and Australia (40.8\%).

\section{Sectors involved}

Innovations were primarily health sector focused (71.3\%), with only $28.3 \%$ of them involving both health and social sectors.

\section{Population groups}

More than half of the innovations were directed at multiple vulnerable population groups (51.0\%), of which

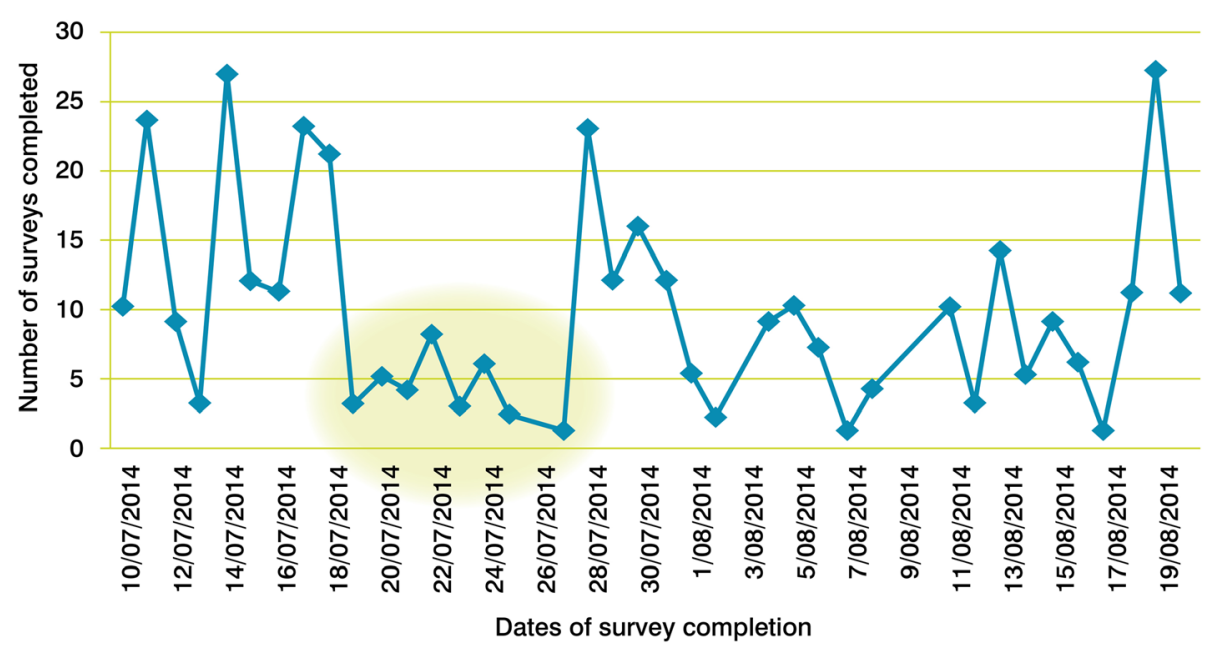

Fig. 4 Number of surveys completed across the survey completion period 
Table 2 Demographics of survey respondents $(N=233)$

\begin{tabular}{|c|c|c|}
\hline & Number & Percent \\
\hline \multicolumn{3}{|l|}{ Respondents Country } \\
\hline Canada & 111 & $47.6 \%$ \\
\hline Australia & 100 & $42.9 \%$ \\
\hline Other $^{\mathrm{a}}$ & 22 & $9.4 \%$ \\
\hline \multicolumn{3}{|l|}{ Respondents gender } \\
\hline Female & 167 & $71.7 \%$ \\
\hline Male & 64 & $27.5 \%$ \\
\hline Rather not say & 2 & $0.9 \%$ \\
\hline \multicolumn{3}{|l|}{ Respondents age } \\
\hline $18-25$ & 11 & $4.7 \%$ \\
\hline $26-34$ & 35 & $15.0 \%$ \\
\hline $35-54$ & 113 & $48.5 \%$ \\
\hline $55-64$ & 62 & $26.6 \%$ \\
\hline 65 or over & 12 & $5.2 \%$ \\
\hline \multicolumn{3}{|l|}{ Respondents qualification } \\
\hline Certificate/diploma & 15 & $6.4 \%$ \\
\hline Postgraduate degree & 168 & $72.1 \%$ \\
\hline Secondary school/High school & 1 & $0.4 \%$ \\
\hline Undergraduate degree & 49 & $21.0 \%$ \\
\hline \multicolumn{3}{|l|}{ Primary area of work } \\
\hline Researcher & 75 & $32.2 \%$ \\
\hline General Practitioner & 59 & $25.3 \%$ \\
\hline Nurse & 58 & $24.9 \%$ \\
\hline Manager PHC & 43 & $18.5 \%$ \\
\hline Other health provider & 20 & $8.6 \%$ \\
\hline Student & 20 & $8.6 \%$ \\
\hline Government & 11 & $4.7 \%$ \\
\hline Volunteer worker & 8 & $3.4 \%$ \\
\hline Educational role & 7 & $3.0 \%$ \\
\hline Not in paid work & 6 & $2.6 \%$ \\
\hline Social worker & 4 & $1.7 \%$ \\
\hline Other & 19 & $8.2 \%$ \\
\hline \multicolumn{3}{|c|}{ How respondents know about the innovation } \\
\hline Know program because designed it & 112 & $47.3 \%$ \\
\hline Know program because delivered it & 107 & $45.1 \%$ \\
\hline Know program from colleague & 40 & $16.9 \%$ \\
\hline Know program from using it & 28 & $11.8 \%$ \\
\hline Know someone who used program & 23 & $9.7 \%$ \\
\hline Know program Internet/Media & 9 & $3.8 \%$ \\
\hline Know program - Other & 28 & $11.8 \%$ \\
\hline
\end{tabular}

${ }^{a}$ Cameroon, India, Indonesia, Ireland, Israel, Italy, Netherlands, New Zealand, Sudan, Switzerland, United Kingdom of Great Britain/Northern Ireland, United States of America low income individuals and families (35.0\%), people living with a chronic disease (33.0\%), homeless individuals (28.0\%) and indigenous communities (27.5\%) were most frequently targeted. Approximately $10.0 \%$ of innovations did not focus on a particular population group.

\section{Settings}

Around half $(50.8 \%)$ the innovations identified were delivered in the community health setting, $40.0 \%$ in the General Practice or Family Medicine Group setting, and $29.2 \%$ in the mobile/outreach clinic setting. The majority of innovations were delivered in multiple settings (57.1\%).

\section{Implementation level}

Almost all innovations were operating at the practice or community level (90.4\%). Only $7.1 \%$ were implemented at a regional level (state, province) and $2.5 \%$ at a national level.

\section{Funding sources}

Most initiatives reported receiving government funding (76.8\%) and around one third reported receiving funding from non-governmental organisations (NGOs) (30.4 \%). Innovations were mainly reported as being funded by a single source $(68.8 \%)$.

\section{Primary dimensions of access addressed}

Detailed features of innovations relating to dimensions of access are presented in Table 4. Overall, the majority of innovations addressed dimensions of access pertaining to the supply-side only (72.9\%), a very small percentage of innovations solely addressed demand-side dimensions of access $(0.8 \%)$ and slightly more than a quarter of innovations $(26.3 \%)$ addressed both supply- and demandside dimensions.

\section{Supply-side dimensions of access}

When looking specifically at the supply-side dimensions of accessibility of services, appropriateness (65.4\%), approachability (55.8 \%), and availability and accommodation $(46.7 \%)$ appeared as the most commonly addressed dimensions reported in the descriptions of innovations. The majority of innovations (95.0 \%) addressed between 1 and 3 supply-side dimensions.

\section{Demand-side dimensions of access}

Most descriptions provided by the respondents did not feature demand-side abilities of patients or populations to access services $(72.9 \%)$. When identifiable in the descriptions of innovations, the most frequently reported demand-side dimension was ability to engage (19.6\%), followed by ability to perceive $(10.0 \%)$ and ability to seek $(9.6 \%)$. 
Table 3 General characteristics of innovations $(N=240)$

\begin{tabular}{|c|c|c|}
\hline & Number & Percent \\
\hline \multicolumn{3}{|l|}{ Country of innovations ${ }^{a}$} \\
\hline Canada & 108 & $45.0 \%$ \\
\hline Australia & 98 & $40.8 \%$ \\
\hline Other & 34 & $14.2 \%$ \\
\hline \multicolumn{3}{|l|}{ Sectors involved } \\
\hline Health & 171 & $71.3 \%$ \\
\hline Social & 1 & $0.4 \%$ \\
\hline Both & 68 & $28.3 \%$ \\
\hline \multicolumn{3}{|l|}{ Population groups targeted ${ }^{b}$} \\
\hline Low income individuals/families & 70 & $35.0 \%$ \\
\hline People living with a chronic disease & 66 & $33.0 \%$ \\
\hline Homeless people & 56 & $28.0 \%$ \\
\hline Indigenous & 55 & $27.5 \%$ \\
\hline People living with a mental health illness & 52 & $26.0 \%$ \\
\hline Refugees & 43 & $21.5 \%$ \\
\hline $\begin{array}{l}\text { Culturally And Linguistically Diverse } \\
\text { communities }\end{array}$ & 34 & $17.0 \%$ \\
\hline Drug users & 34 & $17.0 \%$ \\
\hline Elderly & 34 & $17.0 \%$ \\
\hline Children/Adolescents & 32 & $16.0 \%$ \\
\hline People with disability & 24 & $12.0 \%$ \\
\hline Victims of violence/abuse & 21 & $10.5 \%$ \\
\hline Lesbian Gay Bisexual Transgender Intersex & 15 & $7.5 \%$ \\
\hline Pregnant women/maternal health & 11 & $5.5 \%$ \\
\hline Remote/rural communities & 9 & $4.5 \%$ \\
\hline No particular population group targeted & 26 & $10.8 \%$ \\
\hline Multiple population groups targeted & 102 & $51.0 \%$ \\
\hline Other & 20 & $10.0 \%$ \\
\hline \multicolumn{3}{|l|}{ Settings where innovations are delivered ${ }^{b}$} \\
\hline Setting Community Health Centre & 122 & $50.8 \%$ \\
\hline Setting General Practice/Family Medicine Group & 96 & $40.0 \%$ \\
\hline Setting Mobile clinic/Outreach & 70 & $29.2 \%$ \\
\hline Setting at the Home & 64 & $26.7 \%$ \\
\hline Setting NGO & 50 & $20.8 \%$ \\
\hline Setting Telephone & 43 & $17.9 \%$ \\
\hline Setting Hospital & 41 & $17.1 \%$ \\
\hline Setting Online & 21 & $8.8 \%$ \\
\hline Setting School/educational facility & 10 & $4.2 \%$ \\
\hline Setting Shelter & 8 & $3.3 \%$ \\
\hline Setting Other & 47 & $19.6 \%$ \\
\hline Innovation delivered in multiple settings & 137 & $57.1 \%$ \\
\hline
\end{tabular}

Table 3 General characteristics of innovations $(N=240)$ (Continued)

\begin{tabular}{lll}
\hline Implementation level & & \\
Micro & 217 & $90.4 \%$ \\
Meso & 17 & $7.1 \%$ \\
Macro & 6 & $2.5 \%$ \\
Sources of funding & \\
Financed by Government & & \\
Financed by Non-for-profit & 182 & $76.8 \%$ \\
Financed by Private sector & 72 & $30.4 \%$ \\
Financed - I don't know & 21 & $8.9 \%$ \\
Financed by User payment & 19 & $8.0 \%$ \\
Financed - by other & 12 & $5.1 \%$ \\
Number of funding sources involved & 26 & $11.0 \%$ \\
1 & & \\
2 & 163 & $68.8 \%$ \\
3 & 58 & $24.5 \%$ \\
4 & 11 & $4.6 \%$ \\
\hline
\end{tabular}

${ }^{a}$ Cameroon, India, Indonesia, Ireland, Israel, Italy, Netherlands, New Zealand, Sudan, Switzerland, United Kingdom of Great Britain/Northern Ireland, United States of America

${ }^{\mathrm{b}}$ Multiple responses allowed for this question

\section{Paired dimensions}

Most innovations did not target paired supply- and demand-side dimensions of access (77.9\%) - dimensions of accessibility of services were generally not combined with their corresponding abilities of patients/populations to access services. When considering both supply- and demand-side dimensions together, most innovations addressed 3 dimensions or less (84.6\%). Only one fifth of innovations (18.8 \%) targeted 1 pair, and less than $3 \%$ of innovations targeted 2 pairs or more. The most common pairs were appropriateness/ability to engage $(13.8 \%)$ and approachability/ability to perceive $(8.8 \%)$.

\section{Population groups and settings in relation to specific access dimensions}

When looking at the target population groups in relation to the dimensions of access addressed in the reported initiatives, the findings reveal how specific dimensions may relate to the needs of specific groups. For example, initiatives addressing approachability of services targeted vulnerable, marginalised and culturally diverse groups (e.g. homeless people, low income individuals and families, indigenous communities and refugees) for which identifying what services exist that correspond to their needs might be a challenge. In particular, refugees were a predominant population group targeted in interventions addressing the ability of people to perceive the need for care, with components of interventions focusing on health literacy and education to increase 
Table 4 Dimensions of access featured in the descriptions of innovations $(N=240)$

\begin{tabular}{lll}
\hline & Number & Percent \\
\hline Primary dimensions of access addressed & & \\
Supply-side dimensions only & 175 & $72.9 \%$ \\
Demand-side dimensions only & 2 & $0.8 \%$ \\
Both & 63 & $26.3 \%$ \\
Supply-side dimensions of accessibility of services ${ }^{\mathrm{a}}$ & \\
Appropriateness & 157 & $65.4 \%$ \\
Approachability & 134 & $55.8 \%$ \\
Availability and accommodation & 112 & $46.7 \%$ \\
Acceptability & 40 & $16.7 \%$ \\
Affordability & 29 & $12.1 \%$ \\
Number of supply-side dimensions per innovation & \\
0 & 2 & $0.8 \%$ \\
1 & 88 & $36.7 \%$ \\
2 & 76 & $31.7 \%$ \\
3 & 64 & $26.7 \%$ \\
4 & 10 & $4.2 \%$ \\
Abemand-side abilities of patients/populations to access services & \\
Ability to engage & 47 & $19.6 \%$ \\
Ability to perceive & 24 & $10.0 \%$ \\
Ability to seek & 23 & $9.6 \%$ \\
\hline & $6.5 \%$ \\
\hline
\end{tabular}

Number of demand-side dimensions per innovation

$\begin{array}{lll}0 & 175 & 72.9 \% \\ 1 & 36 & 15.0 \% \\ 2 & 18 & 7.5 \% \\ 3 & 10 & 4.2 \% \\ 4 & 1 & 0.4 \%\end{array}$

Overall number of dimensions of access targeted (supply- and demandside combined)

$\begin{array}{lll}1 & 66 & 27.5 \% \\ 2 & 70 & 29.2 \% \\ 3 & 67 & 27.9 \% \\ 4 & 22 & 9.2 \% \\ 5 & 10 & 4.2 \% \\ 6 & 3 & 1.3 \% \\ 7 & 1 & 0.4 \% \\ 8 & 1 & 0.4 \% \\ \text { Paired dimensions of access } & \\ \text { Appropriateness \& Ability to engage } & 33 & 13.8 \% \\ \text { Approachability \& Ability to perceive } & 21 & 8.8 \% \\ \text { Acceptability \& Ability to seek } & 6 & 2.5 \% \\ \text { Availability \& Ability to reach } & 4 & 1.7 \% \\ \text { Affordability \& Ability to pay } & 0 & 0.0 \%\end{array}$

Table 4 Dimensions of access featured in the descriptions of innovations $(N=240)$ (Continued)

\begin{tabular}{lll}
\hline Number of pairs per innovation & 187 & $77.9 \%$ \\
0 & 45 & $18.8 \%$ \\
1 & 6 & $2.5 \%$ \\
2 & 1 & $0.4 \%$ \\
3 & 1 & $0.4 \%$ \\
\hline & \\
an innovation could address more than one access dimension. Therefore, the \\
number of innovations does not totalise 240 for this section of the table \\
ban innovation could address more than one pair of access dimension. \\
Therefore, the number of innovations does not totalise 240 for this section of \\
the table
\end{tabular}

knowledge about health and health systems. When looking at initiatives addressing acceptability of services, Indigenous people were the predominant population group targeted, with interventions giving emphasis to cultural factors determining the acceptability of healthcare services according to their own values, beliefs and norms. People living with a chronic disease were the predominant group in interventions trying to enhance the ability to seek and engage in healthcare services, with components of interventions focusing on enhancing patients' autonomy or aimed at facilitating the participation of patients in their process of care. Populations with complex healthcare needs require interventions which rely on multidisciplinary approaches, integrated network of services and continuity of care processes, which were key components of interventions described as part of initiatives addressing appropriateness of services. No major difference was found in settings where interventions were delivered to address specific dimensions of access. Overall, the community health setting was predominant, alongside General Practices, mobile clinics/ outreach and NGOs almost evenly distributed across all dimensions. The most prevalent components of interventions identified in the survey to further exemplify each dimension of access (supply- and demand-side) are presented in Table 5. Illustrative vignettes were also assembled to represent the different types of innovations reported in the survey (Table 6).

\section{Discussion \\ Globally shared challenges}

This environmental scan identified, in a timely and costeffective manner, a wide-range of potentially promising innovations for improving access to $\mathrm{PHC}$ for vulnerable populations. Similar types of innovations were identified between countries - interventions seem to occur in similar settings, are directed at similar vulnerable groups, and use comparable funding sources. This suggests that different countries may be struggling with common 
Table 5 Components of interventions per access dimension

\begin{tabular}{|c|c|c|c|c|c|}
\hline \multirow[b]{2}{*}{$\begin{array}{l}\text { Supply-side dimensions of } \\
\text { accessibility of services }\end{array}$} & \multicolumn{5}{|c|}{ Components of interventions relating to access dimensions } \\
\hline & Approachability & Acceptability & $\begin{array}{l}\text { Availability and } \\
\text { Accommodation }\end{array}$ & Affordability & Appropriateness \\
\hline \multirow{4}{*}{$\begin{array}{l}\text { Examples of components of } \\
\text { interventions per dimension of } \\
\text { access }\end{array}$} & Navigation and information & $\begin{array}{l}\text { Adaptation to needs of specific } \\
\text { populations }\end{array}$ & $\begin{array}{l}\text { Outreach from } \mathrm{PHC} \text { into } \\
\text { community setting }\end{array}$ & \multirow[t]{4}{*}{$\begin{array}{l}\text { Defraying costs to } \\
\text { patients }\end{array}$} & $\begin{array}{l}\text { Comprehensive PHC team - One Stop } \\
\text { Shop }\end{array}$ \\
\hline & Facilitated referral for services & \multirow[t]{3}{*}{ Community health worker } & $\begin{array}{l}\text { Virtual consultation with } \\
\text { health provider }\end{array}$ & & $\begin{array}{l}\text { PHC network with community } \\
\text { organisations }\end{array}$ \\
\hline & $\begin{array}{l}\text { Proactive identification of } \\
\text { needs (e.g. early health } \\
\text { assessments) }\end{array}$ & & $\begin{array}{l}\text { Expanded scope of practice } \\
\text { of health professionals }\end{array}$ & & PHC Case Manager \\
\hline & Transparency & & $\begin{array}{l}\text { Geographic location of } \\
\text { PHC services }\end{array}$ & & \\
\hline $\begin{array}{l}\text { Demand-side abilities of } \\
\text { patients to access services }\end{array}$ & Ability to perceive & Ability to seek & Ability to reach & Ability to pay & Ability to engage \\
\hline \multirow[t]{2}{*}{$\begin{array}{l}\text { Examples of components of } \\
\text { interventions per dimension of } \\
\text { access }\end{array}$} & \multirow[t]{2}{*}{ Health and service literacy } & $\begin{array}{l}\text { Education and self-management } \\
\text { coaching (e.g. access to education } \\
\text { material or devices to track your } \\
\text { own health) }\end{array}$ & $\begin{array}{l}\text { Transportation options to } \\
\text { access services }\end{array}$ & \multirow[t]{2}{*}{$\begin{array}{l}\text { No out-of-pocket costs } \\
\text { for patients }\end{array}$} & $\begin{array}{l}\text { Proactive role and participation of patients } \\
\text { and carers (e.g. setting goals, priorities and } \\
\text { actions for the healthcare plan) }\end{array}$ \\
\hline & & Peer-support workers & $\begin{array}{l}\text { Connecting with social } \\
\text { groups/social support }\end{array}$ & & $\begin{array}{l}\text { Community governance model (e.g. } \\
\text { community-led services) }\end{array}$ \\
\hline
\end{tabular}


Table 6 Vignettes of the types of interventions

\section{Illustrative vignettes of interventions}

Types of vignette

Innovations that illustrate the most targeted supply-side dimensions

\section{Description of intervention}

Name of the innovation: PACER Model of Primary Mental Health Care

Country of innovation: Australia

Setting: mobile service

Target population: people living with a mental illness

What does it do? PACER is a mobile emergency menta

health program that teams a Police officer with mental

health training and an experienced mental health clinician

to respond to mental

health crises encountered by Police. This program offers improved coordination of activities between emergency services (Ambulance and Police) and the area of mental health services. The PACER team's complementary skill sets ensure personal and community safety

during the crises and skilled in-time assessment, treatment and referral as appropriate.

Name of the innovation: The Alex Community Health Bus Country of innovation: Canada

Setting: mobile service

Target population: low income individuals and homeless people

What does it do? The Alex Community Health Bus is a mobile clinic providing healthcare services to low income individuals and homeless people five days a week. The Alex Health Bus stops at a number of locations on its weekly route, including low-income seniors housing complexes and homeless shelters. It provides healthcare and education services, and facilitates referrals to a wide range of PHC and community organisations. It is also a roaming food bank, with hampers and emergency food on-board for those in need.

Name of the innovation: Bromley By Bow Health Centre Country of innovation: UK

Setting: community organisation

Target population: no particular population group

What does it do? Bromley By Bow Health Centre is a

community organisation in East London, working in one

of the most deprived neighbourhoods of the city. As a

healthy living centre, it offers a wide range of health services

such as consultations with general practitioners and psychologists,

home visits, antenatal and baby clinics, family planning services,

blood clinics, new patient health checks and nurse clinics.

Name of the innovation: Cool Aid Community Health Centre Country of innovation: Canada

Setting: community health centre

Target population: homeless people, people living with a

mental illness or disability, low income individuals, people
Access dimension(s) addressed*

Components of interventions

relating to access dimensions*

Approachability

Acceptability

PHC into community setting

Appropriateness Multi-sectoral network

Approachability

Availability and accommodation Outreach from PHC into

Appropriateness

community setting

Facilitated referral for services

Multi-sectoral network

$\begin{array}{ll}\text { Approachability } & \text { Geographic location of PHC } \\ \text { Availability and accommodation } & \text { services Comprehensive PHC }\end{array}$

Appropriateness team - One Stop Shop

PHC network with community

organisations

Approachability

Acceptability

nsive PHC team -

Appropriateness 
Table 6 Vignettes of the types of interventions (Continued)

facing addiction problems

What does it do? Cool Aid provides primary healthcare,

counseling, dental care and a dispensing pharmacy. These

senvices are provided by a multidisciplinary team and rely on a

holistic approach to healthcare that includes a strong patient-

centered vision, offering opportunities for patients to take part

in their care and making decisions regarding their health. This

team includes doctors and nurses, counselors, a

nutritionist, a psychiatrist, an acupuncturist, a podiatrist, dentists

and dental hygienists, a pharmacist and a pharmacy technician

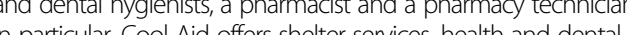

carich

care, mental health and employment suppor, food supplies,

community engagement programs, outreach clinics, peer-based

support groups, harm reduction services, onsite pharmacy with

opiate substitution program, and group medical visits for

ndividuals with complex social, psychiatric and medica

needs.

Name of the innovation: PRIME: A Health Centre for Seniors Country of innovation: Canada

Setting: health centre and residence

Target population: elderly people

What does it do? PRIME: A Health Centre for Seniors offers

a program aimed at keeping seniors healthy and living in

their own homes. PRIME provides alternatives to entering a

personal care home by offering an all-inclusive health service

including medical care, personal care, socialisation

and exercises, after hours support, rehabilitation, day program

and home care coordination, amongst other services for seniors.

Senvices are provided based on a collaborative, multidisciplinary

approach. Transportation is provided to help people attend

the service.

Name of the innovation: Byron Bay homeless breakfast

Country of innovation: Australia

Setting: community organisation

Target population: homeless people

What does it do? Byron Bay homeless breakfast is run once a week at the community centre by volunteers who provide free meals for the homeless and anyone in need in the neighbourhood. The local community health centre staff attend breakfast and use it as an opportunity to provide primary healthcare services to the people who come to breakfast.

Name of the innovation: MyGRiS

Country of innovation: UK

Setting: online

Target population: people living with a mental illness What does it do? MyGRiST is an online tool designed to help people self-assess and manage risks and safety associated with their mental health problems, with the aim of promoting wellbeing. It is a companion too

community setting

In-reach from specialised

services to PHC

Group visits

Patient-centered care

Approachability

Comprehensive PHC team -

Appropriateness One Stop Shop

ntegrated healthcare network

Outreach from PHC into

community setting

Transportation

Ability to perceive

Ability to engage

Approachability

Acceptability

Availability and accommodation PHC network with community

organisations subpopulation
Ability to perceive Ability to seek

Ability to engage

Approachability

Acceptability

Availability and accommodation

Appropriateness 
Table 6 Vignettes of the types of interventions (Continued)

to a suite of clinical tools that have been developed

based on a model of clinical risk assessment founded on

the most recent evidence in the field. MyGRiST collects

identical information to the clinical tools, but using

language and a format co-designed with mental health

service users. This helps empower patients and enables

them to tell their story and communicate risk information

to clinicians. It does this by providing them with a script -

i.e. an output report which clearly indicates where patients'

main concerns are. Reports can be shared online, for purposes

of remote supervision. Patients' personalised output reports

also contain self-management advice and planning.

Name of the innovation: Diabetes Coordination and

Assessment Service

Country of innovation: Australia

Setting: phone-based, primary healthcare organisation

Target population: people living with diabetes

What does it do? Diabetes Coordination and Assessment

Service is a phone-based care coordination service aiming

to promote chronic disease self-management (diabetes in

particular) through screening, triage, assessment, coaching,

referral and follow-up. It assists primary healthcare to

connect people with services that correspond to their

needs. Services also include public diabetes groups,

individual coaching sessions and specialist clinics.

Innovation that combines the most targeted pairs of access

Ability to seek

Ability to engage

Availability and accommodation Naviga follow-ups -

Appropriateness

Self-management coaching Proactive follow-ups

Virtual consultation of health provider

Name of the innovation: Living Well with COPD

Country of innovation: Canada

Setting: online

Target population: people living with chronic obstructive

pulmonary disease (COPD) and their family

What does it do? Living Well with COPD is a self-management

education program developed to help people living with

COPD and their family to take charge and cope with their

disease, in collaboration with their healthcare team. The goal

is to facilitate the adoption of healthy lifestyle behaviors and

the skills needed to ensure optimal management of COPD

on a day-to-day basis. It provides free access to a large number

of educational modules to help manage COPD and resources

about how to navigate the healthcare system.

Name of the innovation: The HOME study

Country of innovation: Australi

Setting: home-based

Target population: Aboriginal

with complex chronic disease

What does it do? The Home based Outreach chronic disease

Management Exploratory Study (HOMES) explores novel

approaches to address chronic disease management in home-

based outreach settings for Aboriginal and Torres Strait Islander

people. The integrated family-based chronic disease management

program involves the engagement and empowerment of
Ability to perceive

Ability to seek

Ability to engage

Approachability

Affordability

Appropriateness

Self-management coaching Navigation and information Defraying costs to patients

\section{Approachability-Ability}

to perceive

Appropriateness-Ability

Ability to seck

Ability to seek
Outreach from PHC into

community setting

System case manager

Patient-centered care

Comprehensive PHC team -

One Stop Shop 
Table 6 Vignettes of the types of interventions (Continued)

families in the management and prevention of chronic disease; comprehensive needs assessment (family health, social situation and needs, physical healthcare needs and social and emotional wellbeing); and integration of health and health related care delivery to patients and their families to improve health outcomes.

Name of the innovation: IMAGINE

Country of innovation: Canada

Setting: community-based drop-in clinic

Target population: marginalised and underserved communities

What does it do? IMAGINE (Interprofessional Medical and Allied

Groups for Improving Neighbourhood Environment) is an

interprofessional, student-run community health initiative

aimed at promoting and providing holistic healthcare to the

core neighbourhoods of downtown Toronto. It offers outreach

activities with community partners as well as health promotion

educational workshops with clients.

Name of the innovation: AMP (Access to Mental health in Primary care)

Country of innovation: UK

Setting: primary healthcare model implemented in different

health and community settings

Target population: people from underserved groups

What does it do? The aim of the AMP Program is to increase

access to high quality primary care mental health services for people from underserved groups. It provides services that are

based on a patient-centered and culturally responsive approach.

The AMP model is comprised of three core components: 1)

community engagement; 2) primary care quality; 3) psychosocia interventions.

Name of the innovation: The Kalwun Development Corporation Country of innovation: Australia

Setting: community health service

Target population: Aboriginal and Torres Strait Islander people

What does it do? The Kalwun Development Corporation provides

services to Aboriginal and Torres Strait Islander people, based

on a community controlled designed and led approach to the

delivery of accessible, efficient, effective and appropriate

comprehensive primary healthcare. The Kalwun Development

Corporation offers a combination of primary healthcare and

community-based services such as access to general practitioners,

comprehensive screening, onsite allied health services, mob

outreach medical clinic on regular basis, immunisation and

transport services. It also offers a program of care coordination

to support patients with chronic diseases in accessing

necessary services.
Approachability - Ability

perceive

Appropriateness - Ability

to engage

Ability to seek

Student-led services

Comprehensive

PHC team - One Stop Shop

Outreach from PHC into

community setting

Approachability-Ability

to perceive

Appropriateness-Ability

to engage

to engag

Approachability

Acceptability

PHC network with community organisations

Navigation and information

Comprehensive PHC team -

One Stop Shop

PHC research embedded in

continuous quality improvement

Patient-centered care

Community governance model Adaptation to needs of specific ubpopulation

PHC network with community organisations Mobile clinic

Transportation 
Table 6 Vignettes of the types of interventions (Continued)

Innovations that combine multiple access dimensions and bridge social and health sectors
Name of the innovation: Multicultural Health Brokers Country of innovation: Canada

Setting: community organisation

Target population: Immigrants, refugees/new comers

What does it do? The Multicultural Health Brokers Co-operative supports families that are new to Canada to bridge between their own knowledge from their home country and Canada's

health, social services, education, justice, immigration

and employment support systems. The Brokers are a

group of 54 people who represent 22 different cultural and

linguistic communities in Edmonton, Canada. They started as

volunteers and were identified as natural leaders in their

communities, and were brought in as a paid capacity with the Co-operative. The organisation offers a wide range of programs that cover social and healthcare needs.

Name of the innovation: Youth projects - The Living Room Primary Health Service

Country of innovation: Australia

Setting: primary health service, mobile/outreach

Target population: homeless people

What does it do? The Living Room is a Primary Health Service

that provides free healthcare and support to improve the

physical, mental and social wellbeing of individuals who are

homeless or at risk of homelessness, disadvantaged or

marginalised, with complex healthcare needs. It provides

a wide range of services such as health and social assessments, professional nursing care, counselling and active support, first

aid, medication management, and follow up to clients; housing support and referral; shower and laundry facilities; food and

material aid; legal support; and art therapy. It uses an assertive

outreach service model to respond to the after-hours healthcare needs of the homeless community, delivering services in public spaces and crisis accommodation.

Name of the innovation: Grameen PrimaCare

Country of innovation: USA

Setting: primary healthcare service

Target population: immigrant women

What does it do? Grameen PrimaCare is a non-profit

organisation that provides underserved women from low

income immigrant communities with a high-quality, affordable

primary healthcare and health promotion program, empowering

them to lead healthier lives. Grameen PrimaCare is founded on a

comprehensive approach to healthcare, providing its members

with access to a broad range of primary healthcare services,

a wellness centre, healthcare tools and a combination of

discounted senvices. The practice is conveniently located to recruit

women from different cultural backgrounds and its team is

comprised of a bilingual female doctor, two nurse practitioners

and one registered nurse. Also on staff is a team of 10-13

health coaches who work to motivate members to achieve health

Approachability

$\begin{array}{ll}\text { Approachability } & \text { Community health work } \\ \text { Acceptability } & \text { Health service broker }\end{array}$

Availability and accommodation Adaptation to needs of

Appropriateness-Ability specific subpopulation

to engage

specific subpopulation
Outreach from PHC into

community setting

Navigation \& information

Advocacy

Approachability

Affordability

Appropriateness

One Stop Shop

Adaptation to needs of

specific subpopulation

Mobile clinic

Approachability-Ability

to perceive

Acceptability - Ability

to seek

Appropriateness-Ability

to engage

Affordability

Geographic location of PHC

services

Adaptation to needs of specific

subpopulation

Self-management coaching

Virtual monitoring of health

condition

Comprehensive PHC team -

One Stop Shop

PHC network with community

organisations 
Table 6 Vignettes of the types of interventions (Continued)

goals, implement customised care plans, coordinate care amongst

providers and connect members to additional services and

resources. Grameen PrimaCare offers support groups focusing

on wellness education. The curriculum covers a range of topics

that engage members in becoming active participants in

their health. An online platform is also available and allows

members to track their own health and access educational

resources that support their journey towards better health and

well-being.

Name of the innovation: The Blue Mountains Aboriginal healthy for life program

Country of innovation: Australia

Setting: partnership between community organisations,

community health centres and General Practices

Target population: Aboriginal and Torres Strait Islander people

What does it do? The Blue Mountains Aboriginal healthy for life

program is an Australian Government program that is aimed at

helping Aboriginal and Torres

Strait Islander people improve their health. Its specific objectives

are to enhance the quality of life and health outcomes of

Aboriginal and Torres Strait Islander people living with chronic

and complex illnesses, and to reduce the incidence of such

illnesses over time. The team is made up of two registered

nurses, a male and female Aboriginal outreach worker, a

Aboriginal child and family worker, a Healthy for life

practice/project support officer and a program manager.

The team assists by meeting in the family home or other

preferred location to discuss health issues, providing a link

to health professionals, doctors or specialists, and arranging regular

health checks and transportation to health appointments.

Approachability Acceptability

Appropriateness-Ability

to engage

Facilitated referral for services Adaptation to needs of specific subpopulation Comprehensive PHC team - One Stop Shop

PHC network with community

organisations Transportation

Community governance model 
access-related issues, despite their own specific contextual considerations.

\section{Expected target groups and community health sector focus}

The population groups targeted in the reported innovations are the ones that we would expect from an equity perspective - people whose life trajectories are marked by experiences of social exclusion and poverty, facing complex healthcare and social needs which challenge their abilities to access PHC services. Governments invest in the community health sector to address the needs of vulnerable populations and this study demonstrated that this is a fertile space where innovations occur. However, our findings suggest that community health centres (CHCs) are carrying an unfair share of the burden in conducting this sort of innovative work to meet the needs of vulnerable groups. We also identified that interventions reported as being delivered outside the traditional clinical health service setting were limited, despite recognition that action must take place outside the health sector to address the wide range of social determinants of health which have an impact on health and access to PHC [5].

\section{Supply-side dominance}

Our study also uncovered the supply-side dominance in terms of dimensions of access addressed by current innovative interventions, the latter focused on influencing determinants of access related to characteristics of healthcare organisations and systems [4]. We have demonstrated that demand-side access determinants - trying to enhance patients' and populations' abilities to access services - still receive little attention, despite current evidence suggesting that interventions aiming at improving access should be more patient-oriented, focused on selfmanagement and health literacy approaches [41].

\section{Sustainability risk of NGOs and lack of shared responsibility}

The government was reported as a major funder of the innovations with most other initiatives being funded by NGOs. NGOs' activities often rely on insecure financial situations (e.g. non-recurrent funding) and therefore sustainability is at risk. The private sector was much less represented and the financial support provided to current innovations was usually provided by a single funder, suggesting a lack of shared community-wide responsibility to achieve equity of access to PHC.

\section{Poor integration of social and health determinants of access}

The examples of interventions identified in this study have shown an imbalance between social and health determinants addressed to improve access to PHC; access determinants targeted remaining mainly healthfocused. Equity of access to PHC requires interventions to take into account social and health determinants, the needs of patients and populations, as well as the resources available to them (supply- and demand-side determinants of access). Notwithstanding the fact that this has been recognised at the policy level and reported as a conclusion of several previous studies of access to healthcare [42-44], multisectoral collaboration (e.g. involving police, community hub and health centres) were uncommon in the innovations reported in this study, suggesting limited integration of health and social care for vulnerable populations.

\section{Critical perspective of the access framework}

The Levesque et al. [24] framework used to support analysis was useful in identifying specific access dimensions addressed by the interventions reported in the survey and gave a structure to the work. It was particularly useful in identifying "where" most of the current activity occurs when trying to improve access to PHC for vulnerable populations (supply-side determinants of access), and to pinpoint areas which could benefit from further attention. It helped uncover the disparity between supply- and demand-side dimensions, as well as the lack of pairing of dimensions of access originating from both groups. In providing concrete examples of access interventions mapped against each of the proposed dimension of the framework, our study has strengthened the link between practice and conceptual work in this field. Wider uptake and use of the framework may allow comparison of studies in the future.

However, we encountered challenges in attempting to operationalise the framework. We had to refine the definitions provided for each dimension of access to undertake a more "fine grain" coding of the innovations in this study. Although the Levesque et al. [24] framework conceptualises access with equal importance given to organisational factors, patients' and populations' characteristics, and contexts (Fig. 1), what specifically bridges both sides (supply and demand) is less clear. Furthermore, social determinants of access were not as easily captured by the framework, and multilevel initiatives (micro, meso and macro) were harder to situate. Further conceptual work will help improve the applicability of the framework to the complex interconnections of the health and social structural dimensions of access in the PHC setting. Finally, even though conceptualisations, models and frameworks are now available to assist researchers in apprehending access to healthcare as a complex phenomenon, we still lack evidence on how to generate improved access for vulnerable populations in a 
practical, effective and meaningful way [4]: what works, for whom, under what circumstances.

\section{Study limitations}

The findings from this study need to be considered in light of its limitations. The results are based on responses provided from survey participants (self-reported data), who were invited to report on what they believed to be the most striking components or aspects of an innovation. Therefore, some dimensions of an intervention might not have been represented in the description provided. In terms of survey design, the participants had the option of completing the survey using tick boxes or free text, depending on the question, and we recognise the potential difficulty in statistical analysis with qualitative data mixed with multiple choice options. However, all qualitative data were coded by a single experienced qualitative researcher (LR) and double coding was performed to ensure accuracy. In fact, we believe that the qualitative data were a significant contribution and helped us to identify other population groups and settings of interest, as well as components of intervention which were not as explicit through the multiple choice option compared to the free text description. Furthermore, the level of detail provided about innovations was relatively limited because of the short survey format. In addition, we do not know if the reported initiatives are effective in achieving improved access. The access framework used for analysis also needed to be piloted and refined, even though it was considered useful in identifying key access dimensions addressed by the reported innovations. The initial email database and contact list assembled was based on our existing research networks. Although we "cast a wide net" using a social media campaign to maximise our reach for innovations, a proportion of the reported innovations likely take origin from the current IMPACT research networks and might not be entirely representative of innovations worldwide to improve access to PHC. Furthermore, our findings do not provide a generalisable summary or overview about the breadth or characteristics of innovations to improve access to PHC, particularly as the majority of innovations reported from the survey in fact originate from Canada and Australia.

\section{Implications for research, policy and practice}

Despite its limitations, this study highlights important questions that still need to be addressed in striving for equitable access to PHC for vulnerable populations: What is the optimal combination of supply- and demand-side dimensions of access? How can we decide which dimensions to target, based on what evidence? How can we make those choices taking into account particular settings? What might be the benefits or the risks of integrating: supply- and demand-side dimensions of access, social and PHC sectors, more than one access determinant and paired dimensions? More research is needed to answer these questions. In particular, there is a need for more rigorously undertaken systematic evaluations of initiatives that are developed, taking into account the particular context in which innovations are implemented and having indicators which cover the broad range of access determinants (health and social) for accurate measurement of the effects of intervention components on specific access dimensions. Future direction for research should also focus on testing the pairing of supply- and demand-side dimensions of access.

\section{Aiming towards multisectoral access initiatives}

To have a wider impact and capture the wide range of social and health determinants of access to reach equity, we need to find ways of creating incentives for multiple social and health service sectors to be involved in the efforts directed at enhancing access to PHC. This would be a first step towards acting beyond the government funded community health sector (e.g. financing initiatives for mainstream General Practice). The private sector having been reported as a marginal source of funding for current innovative interventions considered as improving access to PHC, an opportunity exists for further development and raises the question of how to successfully engage with and incentivise funders across the public and private sectors to promote shared involvement and responsibility towards equity of access to PHC. One way forward could be to further support multisectoral collaboration to develop multifaceted interventions delivered at multiple levels [4], in different intervention settings which are not solely health-oriented. While continuing to work with those population groups who visit $\mathrm{CHCs}$ and General Practices, this would involve developing interventions where people live (e.g. home-based interventions), work (e.g. workplace interventions), or study (e.g. school-based intervention).

\section{Joining forces to address global access issues \\ Considering that similar access issues are experienced globally, sharing knowledge and strategies on how to improve access is likely to be useful, facilitating learning from each other's successes and challenges. Joining forces in developing collaborative research programs and communities of interest could be a way to achieve this.}

\section{Becoming more effective at engaging patients and populations to generate access}

There is a need to demonstrate effective strategies to engage with vulnerable groups in a meaningful way - i.e. in a way that is empowering and allow them to take an active role in defining their priorities, goals and needs 
and reaching out to resources that can help them achieve this [45]. This could involve developing and rigorously evaluating initiatives with end-users, based on collaborative, participatory and co-design approaches. An opportunity exists to critically reflect on the potential risk of disempowerment and further vulnerabilisation of patients who are still not systematically involved as partners in identifying ways to improve access to $\mathrm{PHC}$ with consideration to their needs.

\section{Conclusions}

This environmental scan was useful in identifying a wide range of innovations to improve access to PHC for vulnerable populations. It demonstrated that most of the current attempts at improving access to PHC involve supply-side determinants of access, to transform the way that health systems, organisations and services function. Efforts directed at enhancing abilities of patients and populations to access services (demand-side determinants) were much less prominent. Promising interventions aiming towards equity of access to PHC could expand to take into account social and health determinants of access, the specific needs of patients and populations, as well as resources available to them, using multifaceted, multilevel and multisectoral approaches. The effectiveness of interventions combining supply-side determinants, demandside determinants and paired dimensions on improving access to PHC remains unknown and more evidencebased research around this topic is needed to close the equity gap and help vulnerable populations to get access to services that correspond to their needs.

\section{Endnotes}

${ }^{1}$ The notion of vulnerability is conceived here as a combination of conditions, social trajectories and political contexts which make it difficult for people to gain control over their lives, take up challenges to improve their situation and achieve the full potential of their lives [46], in opposition to being solely the result of individual characteristics.

\section{Additional file}

Additional file 1: IMPACT Study Online Survey Questionnaire. Full Online Survey Questionnaire. (PDF 178 kb)

\section{Competing interests}

The authors declare that they have no competing interests.

\section{Authors' contributions}

LR undertook this study as part of her postdoctoral research fellowship at the Primary Care Research Unit, Department of General Practice, University of Melbourne (Australia). JG was lead investigator for this study which was developed in collaboration with JF, JH, GR and JFL on behalf of the IMPACT team. KD led quantitative analysis of innovations. All authors participated in the preparation of the manuscript, providing written comments on drafts and approving the final version.

\section{Authors' information}

LR is a Postdoctoral Research Fellow at the Primary Care Research Unit, Department of General Practice, University of Melbourne (Australia). JG is Professor and Head of the Department of General Practice at the University of Melbourne. JF is Associate Professor and Principal Research Fellow at the Department of General Practice, University of Melbourne. JH is Associate Professor and Chair of the Family and Community Medicine Research Centre at St. Mary's Hospital and McGill University (Canada). GR is Professor, Head of the School of Primary Health Care and Director of the Southern Academic Primary Health Care Research Unit at Monash University (Australia). JFL is Chief Executive Officer at the Bureau of Health Information and Conjoint Professor at the Centre for Primary Health Care and Equity, UNSW (Australia). KD is Senior Research Assistant and Data Manager at the Department of General Practice, University of Melbourne.

\section{Acknowledgements}

In addition to the authors listed, the IMPACT study acknowledges the commitment provided by the entire research team and partnering communities of practice in Canada and Australia. A special thank you to Ben Harris-Roxas for his advice on the development of the social media campaign and to Sarah Descôteaux for her work with the survey logo and background designs and comments on draft versions of the paper. We also wish to thank Kathryn Steel for her work in designing Figures and Graphs for this paper, and Mylaine Breton for reviewing French survey responses at a preliminary stage of analysis. IMPACT - Improving Models Promoting Accessto-Care Transformation program is funded by the Canadian Institutes of Health Research (TTF-130729) Signature Initiative in Community-Based Primary Health Care, the Fonds de recherche du Québec - Santé, and the Australian Primary Health Care Research Institute, which is supported by a grant from the Australian Government Department of Health, under the Primary Health Care Research, Evaluation and Development Strategy. The information and opinions contained in this paper do not necessarily reflect the views or policy of these funding agencies.

\section{Author details}

${ }^{1}$ Primary Care Research Unit, Department of General Practice, Faculty of Medicine, Dentistry and Health Sciences, University of Melbourne, 200, Berkeley street, Melbourne, VIC 3004, Australia. ${ }^{2}$ St. Mary's Research Centre, 3830 Avenue Lacombe, Hayes Pavilion, suite 4720, Montreal, Qc H3T 1M5, Canada. ${ }^{3}$ School of Primary Health Care, Monash University, Building 1, 270 Ferntree Gully Road, Notting Hill, VIC 3168, Australia. ${ }^{4}$ Bureau of Heath Information, Level 11, Sage Building, 67 Albert Avenue, Chatswood, NSW 2067, Australia. ${ }^{5}$ Centre for Primary Health Care and Equity, UNSW, Sydney 2052, Australia.

Received: 20 November 2015 Accepted: 3 April 2016

Published online: 12 April 2016

References

1. WHO. The World Health Report 2008. Primary Health Care - Now More Than Ever. Geneva, Switzerland: WHO; 2008

2. Starfield B, Shi L, Macinko J. Contribution of primary care to health systems and health. Milbank Q. 2005:83:457-502.

3. Meyer BS, Luong TCN, Mamerow L, Ward PR. Inequities in access to healthcare: analysis of national survey data across six Asia-Pacific countries. Health Serv Res. 2013;13:238.

4. Comino EJ, Davies GP, Krastev Y, Haas M, Christl B, Furler J, Raymont A, Harris MF. A systematic review of interventions to enhance access to best practice primary health care for chronic disease management, prevention and episodic care. BMC Health Serv Res. 2012;12:1-9.

5. Harris MF, Harris E, Roland M. Access to primary health care: three challenges to equity. Aust J Prim Health. 2004;10:21-9.

6. Hart JT. The inverse care law. Lancet. 1971;1:405-12.

7. WHO. Preamble to the Constitution of the World Health Organization. New York, USA: Author; 1946

8. Arcaya MC, Arcaya AL, Subramanian SV. Inequalities in health: definitions, concepts, and theories. Glob Health Action. 2015;8:1-12.

9. Braveman P. Health disparities and health equity: concepts and measurement. Annu Rev Public Health. 2006;27:167-94.

10. Sen A. Why Health Equity? In: Anand S, Fabienne P, Sen A, editors. Public Health, Ethics, and Equity. Oxford: Oxford University Press; 2006. 
11. WHO. Jakarta Declaration on Leading Health Promotion into the 21st Century. Geneva, Switzerland: World Health Organization; 1997.

12. WHO. The Bangkok Charter for Health Promotion in a Globalized World. Geneva, Switzerland: World Health Organization; 2005.

13. Moore G, Showstack J. Primary care medicine in crisis: towards reconstruction and renewal. Ann Intern Med. 2003:138:244-7.

14. Haggerty JL, Pinneault R, Beaulieu MD, Brunelle Y, Gauthier J, Goulet F, Rodrigue J. Practice features associated with patient-reported accessibility, continuity, and coordination of primary health care. Ann Fam Med. 2008;6:116-23.

15. Harris MF. Access to preventive care by immigrant populations. BMC Medicine. 2012;10:1-2.

16. Hogg W, Lemelin J, Graham ID, Grimshaw J, Martin C, Moore L, Soto E, O'Rourke K. Improving prevention in primary care: evaluating the effectiveness of outreach facilitation. Fam Pract. 2008;25:40-8.

17. Lamarche PA, Pineault R, Haggerty JL, Hamel M, Levesque J-F, Gauthier J. The experience of primary healthcare users: A rural-urban paradox. Can J Rural Med. 2010;15:61-6.

18. Spike EA, Smith MM, Harris MF. Access to primary health care services by community-based asylum seekers. Med J Aust. 2011;195:188-91.

19. Strumpf E, Levesque J-F, Coyle N, Huthcison B, Barnes M, Wedel RJ. Innovative and Diverse strategies toward Primary Care Reform: Lessons learned from the Canadian Experience. J Am Board Fam Med. 2012;25(1): S27-33.

20. Levesque J-F, Pineault R, Hamel M, Roberge D, Kapetanakis C, Simard B, Prud'homme A. Primary care affiliation and unmet needs for healthcare services for vulnerable populations: insights from a population-based survey in Quebec province. BMC Fam Pract. 2012;13:1-11.

21. Schoen C, Davis K, DesRoches C, Donelan K, Blendon R, Strumpf E. Equity in health care across five nations: summary findings from an international health policy survey. Issue Brief. vol. 388. pp. 1-7: Commonwealth Fund; 2000:1-7.

22. Veugelers PJ, Yip AM. Socioeconomic disparities in heath care use: Does universal coverage reduce inequalities in health? J Epidemiol Community Health. 2003;57:424-8.

23. Commission on Social Determinants of Health. Closing the gap in a generation: Health equity through action on the social determinants of health. Geneva, CH: In Final report to the CSDH : World Health Organisation; 2008.

24. Levesque J-F, Harris MF, Russell G. Patient-centred access to health care: conceptualising access at the interface of health systems and populations. Int J Equity Health. 2013;12:1-9.

25. Penchansky R, Thomas WJ. The concept of access: definition and relationship to consumer satisfaction. Med Care. 1981;19:127-40.

26. Daniels N. Equity of Access to health care: some conceptual and ethical issues. Milbank Q. 1982;60:51-81.

27. Aday LA, Andersen RA. A framework for the study of access to medical care. Health Serv Res. 1974;9:208-20.

28. Andersen RM. Revisiting the behavioral model and access to medical care: does It matter? J Health Soc Behav. 1995;36:1-10.

29. Gulliford M, Figueroa-Munoz J, Morgan M, Hughes D, Gibson B, Beech R, Hudson M. What does 'access to health care' mean? J Health Serv Res Policy. 2002;7:186-8.

30. Frenk J. The concept and measurement of accessibility. In: White KL, Frenk J, Ordonez C, Paganini JM, Starfield B, editors. Health Services Research: An Anthology. Washington, USA: Pan American Health Organization; 1992. p. 858-64

31. Goddard M, Smith P. Equity of access to health care services: theory and evidence from the UK. Soc Sci Med. 2001;53:1149-62.

32. Braveman PA. Monitoring Equity in Health and Healthcare: A Conceptual Framework. J Health Popul Nutr. 2003;21:181-92.

33. Oliver A, Mossialos E. Equity of access to health care: outlining the foundations for action. J Epidemiol Community Health. 2004;58:655-8.

34. Waters HR. Measuring equity in access to health care. Soc Sci Med. 2000;51:599-612.

35. Graham P. Evitts T. Thomas-MacLean R. Environmental scans. How useful are they for primary care research. Can Fam Physician. 2008;54:1022-3.

36. Haddad S, Mohindra K. Access, opportunities and communities: ingredients for health equity in the South. In: Public Health and International Justice Workshop. New York: Carnegie Council on Ethics and International Affairs; 2002.
37. Shengelia B, Murray CJL, Adams OB: Beyond access and utilization: defining and measuring health system coverage. In Health Systems Performance Assessment. Debates, methods and empiricism. Edited by Murray CLL, Evans DB. Geneva, Switzerland: WHO; 2003:221-2

38. Musgrove P. Measurement of equity in health. World Health Stat Q. 1986:39:325-35.

39. Pope C, Ziebland S, Mays N. Qualitative research in health care: Analysing qualitative data. Br Med J. 2000;320:114-6.

40. StataCorp. Stata statistical software: release 12. StataCorp LP. College Station, TX; 2011.

41. Lorig K, Ritter PL, Pifer C, Werner P. Effectiveness of the Chronic Disease Self-Management Program for Persons with a Serious Mental IIIness: A Translation Study. Community Ment Health J. 2013;50:96-103.

42. Mooner $\mathrm{G}$. Is it not time for health economists to rethink equity and access? Health Econ Policy Law. 2009:4:209-21.

43. McCoy D, Sanders D, Baum F, Narayan T, Legge D. Pushing the international health research agenda towards equity and effectiveness. Lancet. 2004;364:1630-1.

44. Sanders D, Baum F, Benos A, Legge D. Revitalising primary healthcare requires an equitable global economic system-now more than ever. J Epidemiol Community Health. 2011;65:661-5.

45. Coulter A, Ellins J. Effectiveness of strategies for informing, educating, and involving patients. BMJ. 2007;335:24-7.

46. Delor F, Hubert M. Revisiting the concept of vulnerability. Soc Sci Med. 2000;50:1557-70.

\section{Submit your next manuscript to BioMed Central and we will help you at every step:}

- We accept pre-submission inquiries

- Our selector tool helps you to find the most relevant journal

- We provide round the clock customer support

- Convenient online submission

- Thorough peer review

- Inclusion in PubMed and all major indexing services

- Maximum visibility for your research

Submit your manuscript at www.biomedcentral.com/submit 